\title{
Circunscripciones distritales locales e inequidad de la representación: el caso de Baja California, 1992-2004
}

\author{
Leopoldo Martínez Herrera*
}

\begin{abstract}
Resumen. No obstante los avances reformistas en materia del sistema electoral, existen temas aún no resueltos. En el caso de México, y en medio de un debate acerca de nuestra transición, situamos el tema de la sobrerrepresentación distrital, el cual por generar efectos múltiples configura un punto de profunda discusión ya que atañe tanto al sistema de representación como a la integración de la Cámara y al sistema de partidos, pero sobre todo pone a debate la premisa "un ciudadano, un voto", es decir, el principio de la igualdad democrática, que traducido al campo electoral significa asignarle, como afirma Bovero, una cuota igual de valor de decisión a cada uno de los ciudadanos. Para el caso de Baja California, proponemos demostrar que los temas relacionados con la deficiente representación distrital, la integración partidaria de la Cámara de Representantes y, en consecuencia, el atrofiamiento del sistema de partidos siguen vigentes como problemas de una transición que no ha podido trascender los márgenes de la dinámica de la política y del poder de las regiones y localidades. El estudio incluye el análisis de la estructura territorial-demográfica de la representación legislativa de Baja California tomando como referente metodológico lo que para fenómenos similares ha realizado Diego Reynoso, investigador de FLACSO.
\end{abstract}

Palabras clave: equidad, sobrerrepresentación, subrrepresentación, voto, ciudadano

\begin{abstract}
Regardless of the reformist advancements of the election system, there are still unresolved issues. In the case of Mexico and in the midst of a debate on our transition process we place the issue of district overrepresentation, wich by generating multiple effects configures a point of deep discussion thus concerning the system of representation, the integration of the house of representatives, the parties system and above all it puts a debate on the following premise: "a vote per citizen", that is, the principle of equalness in democracy, which translated to the field of elections means, as Bovero stated, assigning an equal-valve decition quota to each citizen. In the case of Baja California, our purpose is to demonstrate that the issues related to the deficient district representation, the integration of the parties within the house of representatives, and as a consequence the athrophy of the parties system continue to be an actual problem on this transition process that haven't been able to trascend the margins of regional and local dynamics of politics and power. This study includes an analysis of territorial-demography of legislative representation of Baja California, taking as a reference all research undertaken on similar phenomena by Diego Reynoso, FLACSO researcher.
\end{abstract}

Keywords: equity, over-representation, sub-representation, vote, citizen

* Instituto Estatal Electoral. Correo electrónico: leomtz@jd01-bc.ife.org.mx 


\section{Introducción}

El presente trabajo tiene como objetivo iniciar en Baja California estudios electorales que se relacionan con el problema de la representación cameral, pues en la ruta de la transición democrática que hemos emprendido, dos campos de estudio han sido poco abordados por los analistas y académicos:

a) Las complejidades de la dinámica transicional en las localidades que patrocinaron en su lugar una sobreatención a los vectores nacionales.

b) Por otro lado, los temas de los sistemas electorales constituyen serios nudos gordianos que deben ser desatados, es decir, existe una agenda demasiado copiosa por lo que hace al esfuerzo y reformas al sistema electoral nacional y a los sistemas electorales locales.

Los olvidos señalados han propiciado una convicción que festejó por anticipado, después de la alternancia en la presidencia de la República, el final de la transición y la llegada a punto de la democracia.

Pocos años transcurrieron después de tal declaración para que nos percatáramos de que existen no pocos obstáculos y procesos incompletos antes de declarar que la nuestra es una democracia sustentable.

La defectuosa representación -debida a diseños de las circunscripciones distritales sin atender con cierta cercanía al principio fundamental de la democracia: igual cuota de valor al voto de los ciudadanos- se traduce en una tensión con las distintas prácticas de las cuotas de asignación de la representación en las unidades subnacionales.

En la primera parte de este ensayo se pone a debate la paradoja del principio de la igualdad del voto, a partir de otro que le antecede que es la igualdad política del ciudadano. La actualización de este debate me parece imprescindible pues la presencia del fenómeno de la sobre y la subrrepresentación legitima esta discusión en tanto dicha práctica pone de manifiesto las situaciones pragmáticas con las que se vulnera este principio; incluso puesto así, éste es uno de los motivos y 
hallazgos que conducen este trabajo. De alguna manera, el sesgo de la representación pretende ser origen y fin de la inequidad que se expresa en los ciudadanos del principio en cuestión: cuota igual de valor para cada ciudadano.

La segunda parte principia con un alegato en cuyo centro se encuentra la dualidad de posicionamientos de aquellos que abogan a favor del fenómeno de malaporcionamiento y aquellos que lo combaten con argumentos sólidos. Enseguida se establecen las comparaciones de los diferentes índices que se utilizaron para medir el grado de sobrerrepresentación y subrrepresentación que acusan los cinco municipios del estado de Baja California durante el periodo 1992-2004.

Además de indicadores simples, se utilizarán otros cuyo uso resulta habitual en casos similares como es el índice DIFMAP, así como la tasa de desviación cuyo significado se encuentra descrito en esta misma parte del estudio.

Desentrañar este fenómeno es llegar hasta las últimas consecuencias, y esto implica determinar los efectos que éste origina en el sistema de partidos así como la medida de su inclusión en la Cámara de Diputados; esto último lo quedo a deber por falta de espacio, pero se abordará en una segunda parte de este estudio.

Una precisión que me parece oportuna hacer es en el sentido de la carencia que existe en Baja California de estudios cuyo campo de preocupación sea el sistema electoral, en especial el tema de la sobre y la subrrepresentación y las unidades distritales. La aridez en esta área probablemente ha propiciado la proliferación del fenómeno pues los partidos políticos no han acusado lo inicuo que resulta tanto para la sociedad como para ellos mismos la persistencia de esta pauta. Es por ello que el presente ensayo pretende a un mismo tiempo la exploración y la descripción de tales prácticas a efecto de alentar los estudios que en esta ruta indagatoria se puedan realizar en el futuro.

\section{La igualdad del voto: ¿un factor de tensión de la democracia electoral?}

En fecha reciente, en el número de diciembre de 2005 de la revista Este País, Elena Varela escribe un artículo al cual con gran tino denomina 
"Penélope y la Democracia Mexicana". El giro metafórico no puede ser más certero, porque como dice la autora: "más preocupante es todavía que en estos momentos sigamos discutiendo los mismos temas que años atrás".

Con ello Elena Varela no hace sino ratificar la legitimidad del tema sobre los diversos aspectos que siguen siendo, desde hace más de un lustro, asuntos pendientes de la agenda de mutaciones que no se han resuelto, no obstante los avances reformistas en materia del sistema electoral, sólo para referirme a este campo institucional del sistema político mexicano.

Abundando en el tema, Andreas Schedler, un puntilloso y a veces incómodo autor para los transitólogos, señala que "durante las transiciones no existe la certeza de que se establecerán reglas democráticas". A lo anterior me permito agregar que a veces no se establecerán de ninguna índole (democráticas o autoritarias), sino que permanecerán las que ya existían.

En el marco de este debate en que se encuentra nuestra transición, queremos situar el tema de la sobrerrepresentación distrital, el cual, por generar efectos múltiples, configura un punto de profunda discusión ya que atañe tanto al sistema de representación como a la integración de la cámara y al sistema de partidos, pero sobre todo que pone a debate una de las premisas que a través del tiempo ha servido como componente sustancial de la democracia moderna: "un ciudadano, un voto", es decir, el multicitado principio de la igualdad democrática que, traducido al campo electoral, significa asignarle, como afirma Bovero, una cuota igual de valor de decisión a cada uno de los ciudadanos.

Por sí mismo, el tema de la igualdad del voto a partir de la igualdad de los ciudadanos es de tomarse en cuenta con seriedad como elemento de análisis político, como lo vamos a hacer enseguida; sin embargo, el tema de la representación tiene amplios conectores con este principio puesto que, al momento del ejercicio comicial, el voto adquiere la importancia de moneda de cambio a partir de la cual se determina y se traduce, según la fórmula electoral, el número de mandatos que los partidos políticos habrán de adquirir precisamente de acuerdo al caudal electoral que posean. Más allá de los datos duros, el tema de la representación adquiere una gran relevancia en el modelo 
democrático ya que a través de ésta se construye una supuesta relación indisoluble entre el poseedor de la soberanía (los ciudadanos) y el receptor transitorio de ella (los representantes camerales).

Una pregunta elemental podría plantearse a fin de simplificar su comprensión: ¿por qué es importante para los ciudadanos poseer un cuerpo de representantes camerales?

Una primera razón, retomando a Hanna Pitkin, es que los ciudadanos requieren ser representados en la Cámara porque constituyen una parte de la nación en función de intereses agregados, los cuales deben ser incorporados al sistema nacional de expectativas para su deliberación e hipotéticamente integrados a las políticas y acciones de gobierno.

La segunda se sustenta en la expectativa de crecer e influir cada vez más en las decisiones del Congreso y en las acciones gubernamentales, a la vez que existe una relación vinculante entre el representante y los representados en función de que la acción del primero siempre será a favor de los segundos.

Es decir, que la función de la representación con respecto a los representados va en relación directa en una especie de duplicar como fotografía las características e intereses de los segundos, a la vez que esta pretensión hipotética debe traducirse en medidas de cumplimiento y eficacia tanto en los resolutivos camerales como en las acciones del ejercicio gubernamental.

Cabe al final una acotación: lo relevante de la representación es que haya efectividad pues, de esta manera, la representación como función recupera mayor relevancia en términos sustantivos, recayendo en ello tal vez la verdadera representación, al menos en el ámbito político.

En paralelo a la discusión sobre la eficacia de la representación, han surgido otros temas que sin duda enriquecen el debate sobre este asunto.

La legitimidad de la representación constituye otro nudo problemático pues no pocos autores están de acuerdo en que posiciones dicotómicas como inclusión y exclusión también son válidas en esta discusión; así, el debate sobre la inclusión de ciudadanos en el funcionamiento de la representación puede generar dos bandos de argumentaciones y de intelectuales que los defiendan: por un lado, los 
optimistas que aluden a ciertos principios de la democracia como diferencia, equidad y participación, y que sostienen que la inclusión en la representación es una garantía de mayor democracia y de resolución de conflictos; por el otro lado están los pesimistas, que apelando a los mismos principios argumentan en contra señalando que la deliberación entre muchos contribuye a una mayor división, además de que la inclusión sólo compensa políticamente a los ciudadanos, pero no lo puede hacer en el campo económico o social (Reynoso, 2004: 50).

En fin, retomamos de manera superficial los problemas que confronta en sí el tema de la representación sólo para colocar en el justo lugar de importancia este tema y su relación con el tema central de este ensayo, que es la sub y la sobrerrepresentación en los distritos electorales. En otro momento abordaremos con mayor profundidad este tema.

Ahora volvamos sobre el tema principal de este artículo, para lo cual reformulo la pregunta: ¿es la igualdad del voto un factor de tensión de la democracia electoral?

Para comenzar, en cierta forma sí lo es y en el curso de las siguientes líneas pretendo mostrarlo.

No cabe duda de que uno de los aportes más relevantes en el tránsito de los Estados liberales predemocráticos de mediados del siglo XIX en Europa fue la disputa por la concesión y la liberación de los ciudadanos en términos políticos hasta lograr el derecho de voto, aunque éste fuera en forma censitaria y discriminatoria. La presión social y la expansión de las organizaciones obreras lograron poner fin a estas barreras hasta lograr que la igualdad ciudadana ante la ley se conjurara como una canonjía en el ámbito político-electoral.

La evolución y desarrollo de los derechos políticos en el seno de las sociedades democrático-liberales en pleno siglo XX convirtió al voto universal, así como a la igualdad del voto de los ciudadanos, en una pieza fundamental de la democracia contemporánea, con lo cual se constata que la igualdad del voto ciudadano es una pieza clave de dicho modelo.

De hecho, este principio se ha legitimado de tal manera que ahora constituye uno de los parámetros para deducir el carácter democráti- 
co de cualquier sistema político. El peso específico que éste tiene ha dejado de lado, sin embargo, la discusión de algunos aspectos relacionados con su significado sustantivo, así como la extensión de su aplicación en un sistema político determinado.

$\mathrm{Ni}$ qué hablar de la variedad y de los efectos que esto tiene en su práctica y aplicación; sólo cuando nos interesamos en la discusión sobre los sistemas electorales de mayoría y proporcionales es que observamos ya en este ámbito lo que podemos llamar precisamente su carácter tensional.

En un primer momento, quisiera principiar el análisis de la igualdad del voto como una derivación de la igualdad del ciudadano a efecto de desplazarlo gradualmente por la avenida de su transformación en cuotas de representación.

En esta parte de la discusión sobre la igualdad del voto sostendré los argumentos a partir de lo que Bovero señala en su más reciente libro titulado Una gramática de la democracia.

El punto de inicio de esta discusión es el concepto de igualdad. Si acudimos a la democracia clásica, este término se conocía como isonomia, y en este caso específico no había lugar para mayores confusiones por una sencilla razón: la vida privada estaba dominada por la vida pública, por lo que de suyo la isonomia como igualdad se consideraba como exclusiva del campo y de la actividad pública, y por ende de la actividad política.

La discusión terminaba aquí mismo porque no cabía preguntarse por las mujeres y los esclavos. Éstos no era iguales, pero en ello no existía contradicción pues ambos pertenecían al ámbito del poder doméstico y no al político, cuyo dominio correspondía al patrono, es decir, al dueño de la casa.

El problema de la igualdad existe en las sociedades modernas en las que ya ha sucedido y se ha desarrollado la separación de la esfera privada de la pública. Así, la democracia como fenómeno moderno se tuvo y aún se tiene que enfrentar con este dilema de la igualdad.

Bovero nos presta algunas estrategias intelectuales para resolverlo. En un primer apunte señala que en la sociedad actual el concepto de igualdad es un tipo de género que contiene una infinidad de especies y que, entonces, se requiere especificarla estableciendo criterios 
que nos permitan identificar y definir las características de los sujetos (Bovero, 2002: 21).

Se requiere pues contestar las siguientes preguntas: ¿Quiénes son los iguales? ¿En qué cosa son iguales?

Una primera precisión: de acuerdo con lo antes señalado, la igualdad se sitúa como un ideal, incluso como una realidad generalizable en la medida en que sus miembros o los sujetos incluidos comparten las mismas propiedades. Sin embargo, para efectos de una relación y de una circunstancia concreta y enclavada en la condición de la interacción social, la igualdad genérica se traduce en una igualdad específica de la cual, paradigmáticamente, surge el proceso de pertenencia y no pertenencia de algunos sujetos a este principio; ello sucede porque antes hemos construido diferentes criterios que definen las propiedades y atributos sobre la igualdad en distintos campos como la política, la economía, la cultura, etc. De esta manera surgen varias especies de igualdades adjetivas del género universal de la igualdad.

De lo anterior podemos inferir que existe una especie de relación o nexo de relevancia entre el género "igualdad política" y la especie "igualdad del voto" En este caso, el requisito de la igualdad política y su relación con la igualdad del voto queda enunciativamente salvado porque el primero contiene una propiedad estrechamente relacionada con el segundo, es decir, ambos responden al criterio o categoría de lo político.

Si hablamos del derecho y la acción de votar, resulta claro que tenemos que invocar la figura del ciudadano, ya que en cualquier sociedad solamente ellos tienen normativamente asignada esta prerrogativa. De esta manera, podemos lograr la siguiente fórmula: en la sociedad democrática moderna, ¿quiénes son los iguales? Respondemos que los ciudadanos, pero entonces preguntamos: ¿ por qué son iguales? Y la respuesta es: porque tienen derecho sin excepción a participar con una igualdad de cuota para decidir sobre los asuntos del poder político.

La justificación de esta igualdad del voto de todos los ciudadanos componentes de la comunidad política se legitima argumentativamente porque: 
a) Los ciudadanos tienen la atribución de a cada cabeza un voto, es decir, de una cuota igual de participación en el proceso de decisión política.

b) Esta atribución igualitaria parte del supuesto de que los juicios y las opiniones de todos los ciudadanos tienen igual dignidad.

c) Lo anterior parte de la premisa de que las diferencias económicas, sociales y otras no son consideradas como ventajas o desventajas entre los ciudadanos en relación a su dignidad política, lo que garantiza diluir cualquier argumento de desigualdad política (Bovero, 2002: 24-27).

Una vez resuelta la primera pregunta, la segunda también se resuelve pues la cosa en que son iguales los iguales es precisamente en la cuota de valor que tienen todos los ciudadanos en el momento de emitir el voto, siempre y cuando los criterios y la especificidad de un sistema o régimen así lo determinen, en seguimiento de un modelo democrático ya que ésta, la premisa de la igualdad, es uno de sus pilares de sustentación.

El siguiente cuadro no requiere de mayor explicación pues sólo pretende establecer con mayor claridad la manera cómo a partir de la condición universal de un ciudadano se expresa y concretiza la condición del ciudadano, ejerciendo precisamente en condiciones de igualdad el ejercicio del voto, lo cual proviene desde la primera instancia, es decir, desde una condición universal como la que significa la igualdad política de todos los integrantes de una comunidad en un contexto de un país con un modelo democrático.

Por otra parte, atendiendo a una idea que emite Sánchez Navarro, debemos también considerar como tema de análisis el aspecto de la

Cuadro 1.

\begin{tabular}{llll}
\hline \multicolumn{1}{c}{ Género } & Criterio definitorio & \multicolumn{1}{c}{ Especie } & Criterio definitorio \\
\hline $\begin{array}{l}\text { Ciudadano } \\
\text { integrante } \\
\text { de la }\end{array}$ & Igualdad política & $\begin{array}{l}\text { Ciudadano con } \\
\text { derechos políticos } \\
\text { vigentes }\end{array}$ & $\begin{array}{l}\text { Igualdad } \\
\text { del voto }\end{array}$ \\
$\begin{array}{l}\text { comunidad } \\
\text { política }\end{array}$ & & & \\
\hline
\end{tabular}


individualización del derecho de la igualdad de voto, a ello se refiere Bovero de la siguiente manera:

[...] la igual distribución del poder de decisión colectiva entre todos los individuos miembros de la colectividad a quienes se refieren las decisiones, justificadas con base en el reconocimiento de que todos los individuos son iguales en la capacidad de juicio político, nos ha llevado a identificar lo que llamaré el principio de la democracia: el principio, o bien el fundamento en el sentido de presupuesto y de punto de partida ineludible de la democracia, es el individuo como sujeto de voluntad racional (Bovero, 2002: 29).

Lo anterior es fundamental en este proceso de legitimar el argumento de la igualdad del voto, pues como señala Bovero, si bien dicho derecho se atribuye como una prescripción o norma y como tal se acepta en su generalidad, para que esta igualdad surta efectos empíricos se tiene que expresar en su individualidad, pues quien es sujeto con dicha atribución es precisamente su propia unicidad; de hecho la construcción de la voluntad colectiva se efectúa sólo a partir de la suma de voluntades individuales.

Esta posición me parece esencial pues de otra manera sería una solución individualista cuyo beneficiario sería siempre sólo el individuo, pero de lo que se trata es de que la decisión política surja del contraste y del consenso, y entonces aquélla se transforma primordialmente a efecto de que tenga un sentido y significado colectivo. Por lo anterior, la voluntad colectiva compromete a todos, incluyendo a las minorías e individuos en desacuerdo a la mayoría, siempre y cuando se preserven las condiciones del disenso y de la confrontación de ideas y juicios.

En el mismo sentido, las violaciones y los obstáculos de dicho derecho de la igualdad del voto se refieren a los sujetos individuales y se combate este hecho de la misma manera; la defensa colectiva de este derecho es entonces una forma táctica.

Lo antes dicho tiene su punto de llegada al momento en que la igualdad del voto se traduce en el procedimiento de distribución de los mandatos entre los ciudadanos. Es aquí donde una pauta del sistema electoral vigente puede generar condiciones que rompen con esta 
premisa de igualdad, pues la comparación entre el efecto-valor del voto emitido por un ciudadano en un distrito con relación al emitido en otro, puede descubrir una mayor o menor asimetría, lo cual nos habla de una ruptura o de un dislocamiento de este principio (Sánchez, 1998: 114).

Los efectos pueden ser de magnitudes dignas de consideración, pues como ya se dijo se trata de la distribución de mandatos que pueden romper ciertos equilibrios de representación por una inadecuada asignación de escaños en las unidades subnacionales (estados, municipios y distritos electorales).

El modelo de distribución de mandatos, entonces, puede juzgarse como inequitativo, y es en este sentido que la igualdad del voto se somete a una tensión porque el principio de igual cuota de valor del voto se ve presionado por otro tipo de factores extraños al factor individuo como sujeto invariable de dicho derecho. La contradicción implícita de esta modalidad es que existen sistemas que lo acepten como medida de excepción, tomándola como incorrecta pero conveniente, con el fin de lograr otros efectos de representatividad alejados del principio cuantitativo de la representación que acompaña a la fórmula: una cabeza, un voto-igualdad de cuota de valor a cada voto.

\section{Fenómeno de la sobre y la subrrepresentación de los distritos electorales en Baja California}

\section{Tesis a favor y en contra}

Diego Reynoso inicia uno de sus textos haciendo alusión al sentido negativo que en una gran parte de los estudios se descubre cuando se analiza este tema de la sobre y la subrrepresentación, mejor conocido en los medios académicos con el nombre genérico de malaporcionamiento ${ }^{1}$ como una traducción no muy afortunada y menos clara del término en inglés malapportionment.

\footnotetext{
${ }^{1}$ Traducción del término inglés malapportionment, que podemos admitir como un fenómeno que se da cuando las unidades geográficas tienen un número de bancas legislativas que no es proporcional a su población.
} 
Pensamos que, sin duda, son los efectos asimétricos que produce un fenómeno de malaporcionamiento y que se traduce en una sobrerrepresentación en unos casos, o bien en una subrrepresentación en otros o ambos a la vez, lo que justifica de sobra la suspicacia o sospecha que provocan eventos como los señalados. La desviación contiene una evidente valoración negativa para aquellos analistas que tienen en mente un modelo ideal en el cual se asume que la prescripción democrática establece la igualdad de valor del voto de los ciudadanos como principio de alta consideración; por lo anterior, podemos entender esto como una forma equívoca de expresión de la decisión política.

No obstante lo anterior, existen otras posiciones que argumentan en contra de lo antes dicho que el malaporcionamiento no sería una patología a la que hay que combatir, sino una especie de mal, es cierto, pero al fin necesario, pues en algunos casos los apremios por cumplimentar el principio de la representación exigen su aceptación por lo menos en forma excepcional.

En las líneas siguientes haremos un breve recuento de aquellos argumentos que están a favor, así como los que están en contra de dichas prácticas.

\section{A) TESIS A FAVOR}

En este campo podemos colocar aquellos argumentos cuyo criterio dominante es el inclusivo, lo que significa que un sistema de decisiones sobre los temas sustanciales de gobierno debe incorporar, de manera segura, a ciertos sectores de la población que se encuentran en desventaja, ya sea por su alta marginalidad o por constituir asentamientos étnicos o territorialmente dispersos. La sobrerrepresentación entonces significa una consideración correctora del valor del voto determinando, en este caso, una mayor preferencia por el tema de la representación que por el principio de la igualdad del voto del ciudadano.

No podemos dejar de lado que tal mecanismo se aparta de la ruta estricta del modelo democrático; sin embargo, como señalan algunos autores, en este caso se trata de una medida de excepción que preten- 
de convalidar el principio de justicia sin romper el esquema normativo que expresa la Constitución. En tal sentido, lo que trata de proteger y justificar es una medida de inclusión que incorpore intereses de un sector de la sociedad que de otra manera se vería excluido.

Un segundo caso que argumenta a favor del malaporcionamiento se relaciona con razones territoriales, así como con ciertas realidades naturales o geográficas.

Esta situación se presenta preferentemente en localidades rurales que contienen en determinados marcos territoriales agrupamientos poblacionales dispersos. Atendiendo a un estricto criterio demográfico para la asignación de la representación política, sin duda que dichas localidades carecerían de representación dado que el número de ciudadanos no sería suficiente de acuerdo con la cuota para su asignación.

En este caso, similar al anterior, se parte del criterio de la mayor inclusividad de la decisión política, por ello los segmentos de población que son detentadores de una serie de intereses, y por lo tanto de una agenda particular, encuentran en este mecanismo de excepción el método para que en la cámara de representantes también se incorporen a la deliberación y a la decisión política las expectativas de dichos agrupamientos.

Podemos agregar a estas razones favorables otras como el respeto a los límites de las unidades subnacionales, esto es, que en un dado caso la determinación de los parámetros distritales de mayoría relativa amenazan con fraccionar o fracturar una ciudad o subunidad nacional de relativa importancia. En este caso se podría aplicar la medida excepcional de incorporarla toda, generando con ello probablemente un fenómeno de subrrepresentación. En tal situación se estaría atendiendo a criterios para conservar la cohesión de las comunidades adscritas a tal unidad subnacional.

Como podemos observar en los casos señalados, si bien es cierto que se admite la generación del malaporcionamiento o se da la sub o sobrerrepresentación, en todos ellos se justifica en razón de un interés general y se establece de manera excepcional; todavía más, esta admisión se hará en forma casuística.

Bien señala el maestro Sánchez Navarro cuando dice: 
Las diferencias entre las circunscripciones sólo se justifican para permitir la toma en consideración de imperativos de interés en general. A la hora de delimitar las circunscripciones para la elección de los miembros de asambleas [...] debe atenderse esencialmente, pero no exclusivamente el criterio demográfico [...] éste, sin embargo, puede ser modificado por otros imperativos de interés general siempre de acuerdo a unos límites (Sánchez, 1998: 41, 46).

El texto anterior tampoco requiere explicación pues es de gran claridad, sin embargo, deja en el aire una pregunta: ¿cuáles son esos límites y en qué medida son admisibles?

\section{B) TESIS EN CONTRA}

El posicionamiento de esta tesis parte del estricto apego al principio de la igualdad del voto, lo que se traduce en la aplicación del criterio al cual el maestro Reynoso denomina "demoorientador", es decir, que la igualdad del voto se garantiza en términos de representación cameral diseñando o configurando las demarcaciones distritales de acuerdo a una media general de ciudadanos en una unidad subnacional, con igual o cercana a ella en cada una de dicha demarcación. La aceptación de esta posición descarta el criterio "terraorientador", el cual permite el malaporcionamiento justificado por razones territoriales, integración étnica o cohesión social en localidades específicas, para construir excepcionalmente circunscripciones con un determinado sesgo de sub y sobrerrepresentación.

Las principales objeciones a la permisividad del sesgo de la representación se relacionan en primer lugar con que aceptar tal medida implica romper con el principio de "igual cuota de valor para cada ciudadano", del cual ya ha dado cuenta Bovero; es decir, que más allá de cualquier justificación casuística, en cada excepción se violenta la norma y el principio clave de la democracia, además de que en la práctica, en términos generales, en las constituciones modernas se establece que éste es el criterio único para constituir la configuración de los distritos electorales. Para todos estos casos, las causales de interés ge- 
neral y bajo ciertas condiciones son siempre excepcionales y constituyen un litigio que puede dilucidarse en tribunales, como ya ha sucedido en nuestro país con la configuración de distritos basado en criterios distintos a los demográficos en el estado de Sonora, lo cual concluyó con un fallo desfavorable para dicho diseño que provino de la Suprema Corte de Justicia (Cossio, 2005: 41).

Por otra parte, parece que el ejercicio de un modelo de malaporcionamiento tiene efectos relacionados con la ventaja que toman los distritos que se encuentran sobrerrepresentados en relación con aquellos que se subrrepresentan, ya que se establece una disputa por los recursos y las políticas gubernamentales con una expresión de desequilibrio por cuanto hace a los ciudadanos afectados o beneficiados; también afecta la magnitud de la importancia de las aportaciones de los conglomerados situados en uno u otro lado, así como el impacto que implica el ejercicio gubernamental cuando con ello se puede beneficiar a comunidades de menor importancia en detrimento de aquellas de mayor dimensión.

Un argumento que rivaliza y se opone a esta expresión de ingeniería electoral se relaciona con la preeminencia y la permisividad de distritos rurales para asignarles una sobrerrepresentación, en detrimento de los distritos urbanos que terminan por ser subrrepresentados generándose una tensión entre ambos, amén de que, de acuerdo con esta teoría, existen oligarquías que obtienen un dividendo por la aplicación de las políticas públicas del Estado (Reynoso, 2004: 94).

El anterior apunte es relevante pues puede abrir una interesante veta de indagación a efecto de constatar esta hipótesis, lo que pudiera medirse a partir de una evaluación de las políticas públicas y presupuestos asignados con una orientación de preferencia a los distritos sobrerrepresentados, o bien en la relación distritos urbanos-distritos rurales.

Por último, si bien es cierto que el fenómeno conocido como gerrymandering ${ }^{2}$ tiene una cierta cercanía con el del malaporciona-

${ }^{2}$ Es una práctica que consiste en reacomodar a los distritos electorales para ampliar la posibilidad de triunfo de un partido político. Se deriva del nombre de Elbridge Gerry, quien siendo gobernador de Massachussets en 1811 publicó una 
miento, una diferencia consistente proviene desde su finalidad en este sentido: el primero se deriva de un diseño territorial que llevó la intención de Elbridge Gerry (gobernador de Massachussets en 1811) de generar una ventaja contra sus oponentes en las elecciones cercanas, mediante ello se concentraron espacialmente los votos a su favor y se dispersaron los de sus contrarios; por su lado, el diseño de malaporcionamiento tiene como finalidades, tal como hemos descrito, permitir que mediante una práctica inclusivista puedan estar representados segmentos de la población que, por causas de marginalidad étnica o dispersión geográfica, no lo estarían, es decir, que en esta segunda opción no se pretende por lo menos en forma evidente favorecer a un partido o a una fuerza política determinada.

Con este último criterio, Dieter Nohlen nos retrata la manera en que en Gran Bretaña, cuna de la democracia parlamentaria, "la representación está ponderada con arreglo a las cuatro regiones (Inglaterra, Escocia, Gales e Irlanda del Norte)" (Nohlen, 1994: 48),

Por lo anterior, si bien es cierto que todo diseño de gerrymandering lleva implícito un sesgo de beneficio deliberado en términos de utilidad para algún actor político, la práctica de malaporcionamiento en cambio no conlleva esa finalidad; esto es, que no toda práctica de gerrymandering implica una sobre o subrrepresentación, como tampoco el malaporcionamiento produce siempre efectos legitimados o benévolos, pues en ocasiones produce efectos dobles como un sesgo en la equidad de la representación, así como también beneficios a alguna fuerza política determinada.

Para el caso de México y a nivel nacional, podemos señalar que a partir de que se crean las nuevas instituciones y autoridades electorales, así como los cuerpos normativos en esta materia, la propia institución establece que el criterio invariable bajo el cual se realizarán los diseños distritales será el poblacional. En segunda instancia, es el Cofipe el que establece que será el Instituto Federal Electoral el que

\footnotetext{
ley que reajustó los distritos de su partidos (demócrata) y vulneró a los de la oposición. El término se compone del apellido del gobernador, Gerry, y mander, que significa "salamandra", pues el mapa resultante semejaba la espalda de tal especie.
} 
realizará los estudios técnicos a efecto de llevar a la práctica dicho ejercicio. De esta manera, el rediseño y la delimitación de los distritos electorales federales se reduce a una operación técnico-poblacional en la cual se establece la media poblacional como cuota mínima para cada unidad distrital; de hecho, este mecanismo técnico permite ambos sesgos, es decir, tanto la sobre como subrrepresentación, ya que el documento normativo (acuerdo del consejo general) establece una tolerancia de $\pm 15 \%$ de población para cada distrito.

Bajo este criterio, también en Baja California opera dicho principio, ya que el criterio poblacional como mandato constitucional nacional debe prevalecer también en las entidades.

Éste puede ser uno de los problemas que se presentan en los diseños distritales que han prevalecido, es decir, una falta de cumplimiento del principio "poblacional", pues en la pesquiza que hemos realizado en el más reciente diseño distrital, el documento normativo del órgano electoral estatal admite otros criterios como el natural, geográfico, cultural, demográfico e histórico.

Con lo que se ha dicho hasta aquí, todo parece indicar que a nivel nacional existe un estricto respeto al criterio "población", de acuerdo a la Constitución, y que en la práctica se legitima un sesgo de $\pm 15 \%$ de sobre y subrrepresentación.

No sucede lo mismo a nivel estatal, ya que en este caso existe una desaveniencia con el criterio institucional; además, como aquí se demuestra, existe una variabilidad específica entre distritos locales de un gran significado, dándose en tal circunstancia un notorio problema de inequidad en la representación.

De alguna manera, lo que queremos también afirmar es que tanto la gerrymandering como el malaporcionamiento son similares en cuanto a forma, pues ambos deliberadamente generan trazos especiales a los distritos electorales, incluso de forma caprichosa e irregulares; sin embargo, en el fondo son contundentemente diferentes, pues la gerrymandering tiene como finalidad la protección de un interés o de un dominio político-electoral, mientras que el malaporcionamiento busca otorgarle representación a un sector determinado o bien realizar un ajuste con el fin de resarcir el principio de equidad política. 
En la siguiente figura podemos observar algunos ejemplos:

Figura 1.

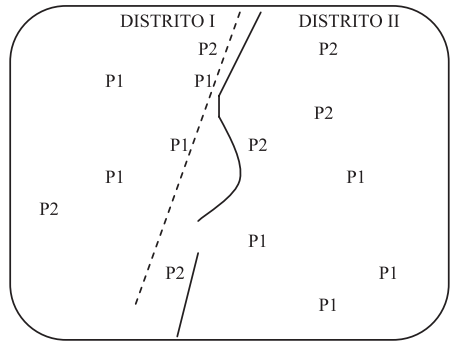

Gerrymandering

En un primer momento, los distritos I y II estaban delimitados por la línea punteada; en esta circunstancia el partido uno (P1) tenía seguro el triunfo en el distrito I, mientras que había riesgo de perder el distrito II por la fuerte presencia electoral del partido dos (P2). El nuevo trazo establecido con línea continua permite que el partido uno (P1) gane ambos distritos. Ello se debe a que se desplaza un bastión del P2 desde el distrito II hacia el distrito I ya que en este último el P1 tiene un importante excedente de caudales electorales que le asegura el triunfo.

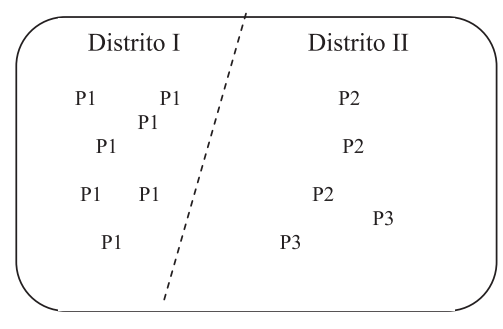

\section{Malaporcionamiento}

En un primer momento tenemos la configuración de un solo distrito I. Sin embargo, a efecto de otorgarle representación a un sector que está asentado en un mayor territorio pero con menores núcleos poblacionales de carácter étnico y marginales (P2) y (P3), se procede a constituir un nuevo distrito (distrito II) dividiendo el distrito I en dos, quedándose en el distrito I el mayor número de asentamientos humanos que son más compactos y de carácter urbano o semiurbano (P1). La línea punteada indica la nueva división en dos distritos.

\section{El malaporcionamiento en Baja California, 1992-2004}

Me parece elemental que iniciemos el estudio de este fenómeno de la sub y sobrerrepresentación distrital con la denominación genérica que le da nombre a este apartado: malaporcionamiento.

Para los efectos anteriores tomaremos la definición de Diego Reynoso, uno de los contados estudiosos de los sistemas electorales que se ha abocado a estudiar este fenómeno que, si bien se presenta 
con cierta frecuencia en nuestro país, es a pesar de ello un campo sumamente árido por cuanto hace a la atención de otros analistas.

El malaporcionamiento se da cuando "las unidades geográficas tienen un número de bancas legislativas que no es proporcional a su población" (Reynoso, 2002: 326).

Lo anterior requiere algunas precisiones que se derivan del concepto en forma complementaria; en primer lugar, las unidades geográficas se identifican con las unidades subnacionales, las cuales, para este efecto, se refieren a los municipios y a los distritos electorales uninominales o de mayoría relativa.

La presencia de este fenómeno tiene dos efectos inmediatos: el primero es que se asume que existe una pauta de ponderación de votos, es decir, que en forma artificial se genera un desbalance en la paridad o valoración igual del sufragio para asignarle un mayor peso a unos votos ciudadanos que a otros, o en otras palabras, se ejercita lo que Reynoso retomando a Monroe denomina una "inequidad electoral" (Reynoso, 2002: 326); el segundo efecto que se manifiesta con esta práctica es la existencia de la sub y de la sobrerrepresentación, lo cual tiene efectos en el sistema de partidos así como en la disputa de la agenda gubernamental y la atención especial y preferencial a ciertas zonas por parte de las instituciones gubernamentales, lo que podremos estudiar en otra ocasión.

En otra parte del ensayo se comenta brevemente la manera en que un sesgo representativo puede traer ventajas o desventajas para los habitantes integrados a una circunscripción distrital afectada por el malaporcionamiento, pues se puede dar el caso de que un partido obtenga varios mandatos debido a una mayor concentración en una determinada zona, si en ella, a través de un diseño erróneo, se constituyen varias unidades distritales apegadas a una cuota menor de ciudadanos que la media estatal; seguramente dicho partido político obtendrá, en consecuencia, una mayor representación y, por ende, un mayor poder, lo cual puede contribuir a encauzar la demanda e influir en la agenda institucional.

Por otro lado, sólo a nivel primario, haré un comentario breve respecto al efecto que un fenómeno de malaporcionamiento provoca al sistema de partidos políticos. 
En efecto, como sabemos, un sistema de partidos se estructura principalmente a partir de dos variables: $a$ ) por las condiciones de diversidad y de pluralidad de una sociedad, lo cual se reproduce con las organizaciones políticas que se constituyen para su representación; y b) por la cantidad de partidos que una sociedad decide actualizar. La pauta de malaporcionamiento puede afectar dichas variables pues los diseños distritales pueden generar exclusiones de algunos segmentos de la población de diversas características e intereses; en consecuencia, la funcionalidad y eficacia de determinados partidos pueden verse reducidas con dicha práctica hasta llegar incluso a su extinción.

Finalmente, una práctica persistente en este sentido por un periodo considerable puede generar un proceso centrípeto en el que la mayoría de los mandatos se adjudiquen solamente a dos o tres fuerzas políticas. Resulta claro que en este caso pueden suceder dos consecuencias: 1. que los partidos sin mandatos a mediano o largo plazo, como ya señalé, seguramente dejarán de existir y 2 . que el sistema de partidos sufrirá un atrofiamiento, pues puede ser que los partidos vulnerados sigan existiendo de manera precaria o artificial.

Como podemos inferir, el primero de los efectos toca la parte normativa del modelo democrático pues introduce la discusión de si en un sistema de este tipo es factible que se violente una de las piezas angulares que le dan sustento como es la igualdad del voto, y siga sin embargo conservando su denominación de democracia ya que, de hecho, con la práctica del malaporcionamiento se violenta el concepto de que "todos los votos deben influir (por igual) en el resultado electoral; éste debe estar formado por la suma de todos los votos" (Kelsen, citado por Alcubilla, 1999: 662).

Por su parte, el segundo efecto tiene mayores implicaciones pragmáticas pues afecta el principio de la representación así como la presencia en el Congreso de los partidos políticos.

En una especie de contabilidad, parece que el malaporcionamiento goza de lo que unos autores denominan un "consenso negativo", y en consecuencia, su práctica reviste una especie de patología de un sistema electoral por cuanto que lógicamente provoca efectos de inequidad en el sistema de representación. Sin embargo, como ya se observó en el apartado anterior, otros autores, aduciendo precisamente a argu- 
mentos de justicia y de aplicación de ciertos principios democráticos -como la pluralidad, la inclusividad y la consideración de minorías- aceptan en circunstancias de excepción el ejercicio que da como resultado la ponderación de votos, provocando en consecuencia la sub y la sobrerrepresentación.

Existe también, por otra parte, la convicción en el campo de la teoría de los sistemas electorales de que no existen modelos que puedan garantizar la igualdad y la equidad en términos absolutos, pues todos ellos tienen incorporados elementos que precursan efectos tanto de desproporcionalidad relativa en la operación de conversión de votos en escaños como aquellos que producen por causa de su trazado territorial la sub y la sobrerrepresentación relativa. Creemos que las condiciones jurídicas, demográficas, naturales y políticas son factores que patrocinan la subsistencia de tales "patologías".

A lo último agregaré algunos elementos. Si bien es cierto que el malaporcionamiento goza de un consenso negativo, en algunos casos, ciertos países como España y Canadá pueden generar mecanismos jurídicos a efecto de constituir alguna unidad distrital que contenga la legitimidad de la desproporcionalidad, como puede ser la protección de alguna etnia o bien que por motivo de estatus socioeconómico sean estos elementos patrocinadores para sesgar un trazo distrital. Otros eventos excepcionales se dan cuando por accidentes geográficos o composición de la naturaleza se pueden generar circunscripciones con rangos poblacionales menores o mayores a la media estatal o nacional, justificándose con el argumento de conservar el principio de región o localidad. Los factores políticos son los que podrían encontrar una menor legitimidad, pues se puede dar el caso de que ello obedezca a una componenda en las altas esferas del poder político a efecto de privilegiar algún coto de votos de un partido, garantizando con ello el apropiamiento reiterado de dicho mandato.

Vale la pena acotar como un marco general de referencia lo que Diego Reynoso señala en el sentido de que podemos aceptar que los sistemas electorales tengan dos modalidades, en un esfuerzo por simplificar una tipología, y que éstos pueden ser permisivos y restrictivos. En este tema, la precisión de Reynoso me parece determinante 
porque el factor definitorio es el acceso o no de los partidos políticos a la cámara representativa.

Los sistemas restrictivos construyen una serie de medidas y barreras legales a efecto de evitar la incorporación de algunos partidos políticos en el órgano de representación; mientras que los sistemas permisivos desbloquean la inserción de los partidos en las cámaras, estableciendo requisitos mínimos y barreras menores para que puedan ser salvadas. Lo anterior también tiene efectos para el fenómeno de diseños distritales, pues puede haber coincidencia entre ellos con trazado excepcional que producen sobrerrepresentación con un partido bastionario que tiene dominio electoral en dicha zona.

Atendiendo al caso de Baja California, enseguida procederemos a invocar los hallazgos que hemos encontrado en una pesquisa que realizamos, con el fin de localizar y medir el fenómeno de la sub y la sobrerrepresentación (malaporcionamiento) en los distritos electorales locales durante el periodo 1992-2004.

El marco especial del estudio son los llamados espacios subnacionales, en este caso, los cinco municipios del estado, así como los 16 distritos electorales locales de mayoría relativa. Los elementos que utilizamos para medir la sub y la sobrerrepresentación son los siguientes índices:

- Map. Es la traducción en un índice cuantitativo de la sub y sobrerrepresentación dada en una unidad subnacional (malaporcionamiento), que pueden ser las entidades, los municipios y los distritos electorales. ${ }^{3}$

Fórmula: $\mathrm{D}=1 / 2 £ 1 \% \mathrm{E}$ - \% M l, en la que

$\mathrm{D}=$ map

$\mathrm{E}=$ Número de electores hábiles por distrito, municipio o estado. $\mathrm{M}=$ Magnitud del distrito o número de diputados por distrito, municipio o estado.

${ }^{3}$ Para este cálculo se sigue la aplicación que hace Diego Reynoso para indicar la similitud con el índice de desproporcionalidad de Loosemore y Hanby, con la variante de que en lugar de la diferencia entre votos escaños de los partidos, aquélla es la diferencia entre el porcentaje de electores del distrito y el porcentaje de escaños que le corresponde a dicha unidad electoral (Reynoso y Villarreal, 2005: 187-188). 
- Difmap. Determina una relación entre lo que representa porcentualmente cada unidad de representación y lo que representan porcentualmente los electores en una unidad subnacional. Fórmula $=\% \mathrm{M}-\% \mathrm{E}$.

En este caso, el ideal es que la diferencia sea siempre igual a cero.

- Indice de desvío. Determina el malaporcionamiento invirtiendo el signo; así, los distritos sobrerrepresentados obtienen signo positivo, mientras que los subrrepresentados obtienen un valor negativo.

Fórmula: Desvio $=[(\% \mathrm{Ml} \%$ EX100 $)-100]$.

En este indicador, dado que la relación directa es el porcentaje de representación que significa $\mathrm{M}$ entre el porcentaje de electores habilitados que representa E, el ideal es que el cociente siempre sea igual a uno para conservar el principio de igualdad del voto.

En el estudio establecimos en forma un tanto convencional que la unidad de medida de los sujetos poblacionales que habría que considerar son los electores habilitados, ya que son ellos los que determinan, a través del procedimiento comicial, la representación en la unidad distrital, municipal o estatal.

La medición del fenómeno motivo de este análisis se realiza en una trayectoria temporal de 1992 a 2004, periodo durante el cual se realizaron cinco procesos electorales para renovar al congreso del Estado, por lo que las magnitudes del cuerpo electoral (E) en cada evaluación trianual coinciden con el listado nominal con el que se realiza cada una de las elecciones; de manera similar, la magnitud de la representación (M) se realiza tomando en cuenta la cantidad de representantes de mayoría relativa que componían la Cámara al momento de la disputa electoral.

Las mediciones que se hicieron para cada caso fueron las siguientes:

- La razón municipal de electores por diputado y la razón estatal de electores por diputado 1992-2004.

- Comparativo de curules asignadas realmente y curules asignadas hipotéticamente en los municipios del estado 1992-2004. 


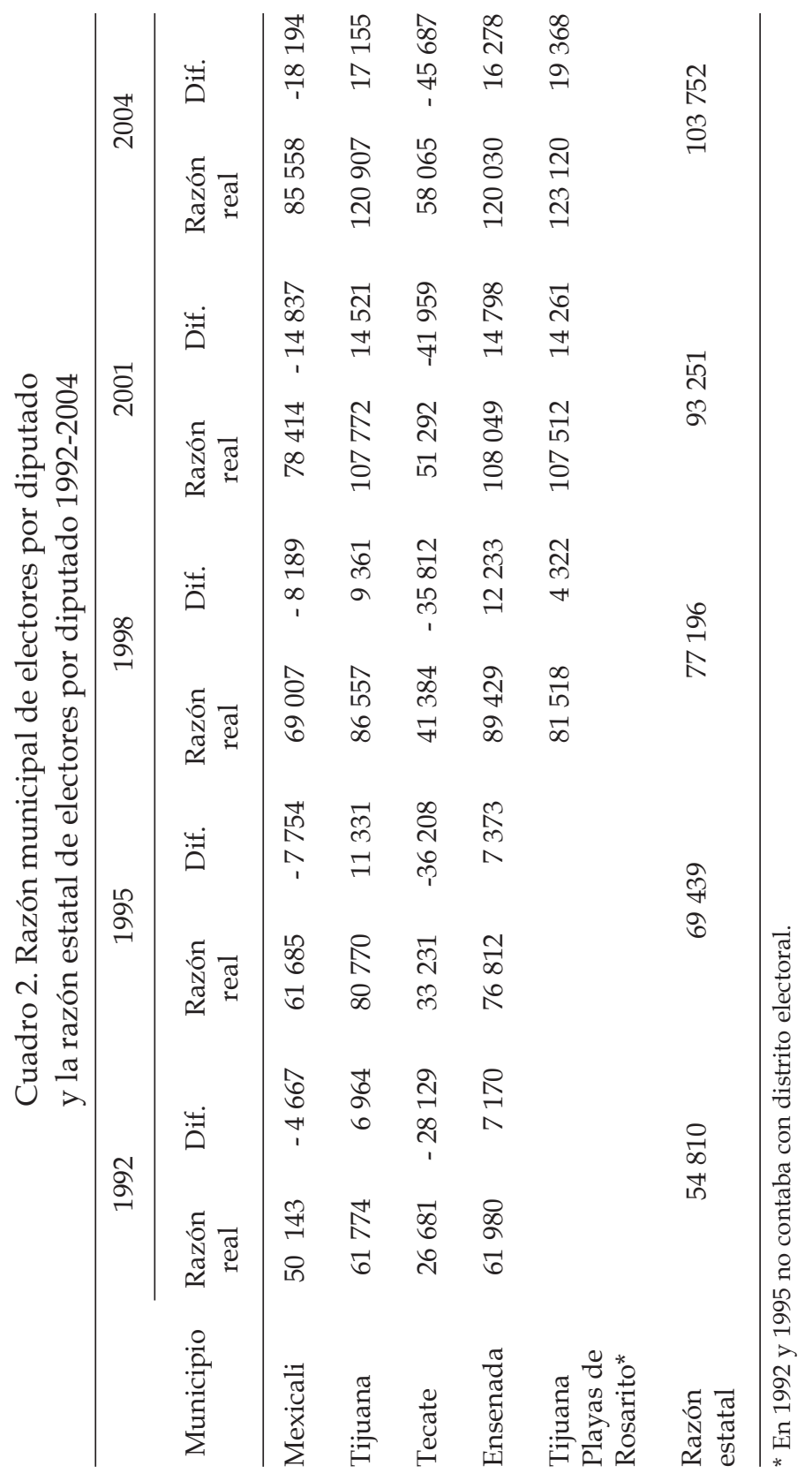


- Indicadores de malaporcionamiento en los municipios del estado 1992-2004.

La razón municipal de electores por diputado y la razón estatal de electores por diputado 1992-2004

Como se puede observar en esta primera presentación de los hallazgos derivados del estudio, tomando en cuenta por cifra de referencia la razón estatal, es decir, el número de electores correspondientes o equivalentes a un distrito electoral y por lo tanto a un integrante de la Cámara, en sus diversos momentos, en este caso en cinco (1992, 1995, 1998, 2001 y 2004), que corresponden a aquellos en los cuales se realiza la elección, esta razón es comparada con la razón municipal que se deriva de dividir el número de electores entre el número de distritos correspondientes al mismo municipio. Se infiere así que durante el periodo de los cinco eventos son los municipios de Mexicali y Tecate los que registran una constante de cifras negativas con relación a la razón estatal, mostrando dicho indicador una tendencia creciente y observándose en el caso de Tecate un diferencial negativo excesivo; a su vez, Tijuana, Ensenada y la zona Tijuana-Playas de Rosarito muestran una tendencia progresiva de electores excedentes, observándose que la zona Tijuana-Playas de Rosarito registra el mayor diferencial, aunque en un menor periodo (1998-2004).

Los datos antes señalados ya, en esta primera instancia, muestran el fenómeno de la sub y la sobrerrepresentación a nivel de las unidades subnacionales en los cinco municipios del estado. Para tales efectos, los municipios de Mexicali y Tecate muestran evidencias de sobrerrepresentación pues la razón municipal, de acuerdo a los distritos que a ellos corresponden, es menor al promedio estatal, es decir, a la razón estatal. Algo similar sucede con los municipios de Tijuana, Ensenada y la zona Tijuana-Playas de Rosarito, pues en estos casos estamos ante la presencia de una subrrepresentación ya que en ellos la razón municipal siempre es mayor que la razón estatal.

Una evaluación final de este aspecto, tomando en cuenta la unidad subnacional municipal y considerando además, de acuerdo a la práctica internacional y nacional, que el 15\% de sub y sobrerrepresentación 
son medidas aceptables, revela que al término del periodo (2004) Mexicali y Tecate rebasan tal cifra con números deficitarios, destacando sobre todo Tecate con una cifra de desfase con relación a la razón estatal de tres veces el tope aceptable. Por su parte, Tijuana, Ensenada y Tijuana-Playas de Rosarito cierran el periodo con cifras positivas arriba de lo aceptado, indicándonos un fenómeno de subrrepresentación.

Los datos muestran tempranamente una práctica irregular que consiste en que los órganos electorales o autoridades responsables de ello no han efectuado -o lo han hecho en forma inadecuada- los ajustes en los diseños distritales para conservar una equidad poblacional entre los municipios y la magnitud de la representación cameral.

Una de las causas fue o ha sido que en lugar de orientarse dentro de un criterio demoorientador que privilegiara la base poblacional, se ha privilegiado o por lo menos ha estado presente algún criterio de utilidad política o algún criterio natural, urbano o geográfico.

Por otra parte, otro aspecto que resulta relevante para el propósito de este ensayo es que en este grupo de indicadores resalta la presencia de un tema en disputa: la igual cuota de valor del ciudadano. Me refiero a que a través de este indicador se registra, en forma evidente, que existen sustanciales disparidades por cuanto hace al principio que está en consideración, pues la comparación de la razón municipal de cada uno de los municipios con relación a la razón estatal indica la asignación desigual del valor del voto en general en el estado, pero si comparamos entre sí las cinco razones municipales resulta más evidente el desacato del principio "igual cuota de valor a cada ciudadano" en dimensiones espaciales más específicas. Lo anterior tiene una connotación negativa pues debido a este sesgo, lo que resulta después de una elección es que el voto ciudadano es una decisión individual sufragada inequitativamente porque es portadora de una mayor o menor cuota de valor.

Lo anterior es digno de consideración si establecemos una metáfora en la que el voto equivale a una moneda de cambio y que a través de una sumatoria mayoritaria se obtiene un escaño o un mandato. De seguir este proceso de sesgo distrital, se puede llegar a la conclusión de que la misma moneda tiene diferentes valores para ciudadanos 
iguales, lo cual en términos de economía implicaría que existe una grave distorsión del mercado y de la expresión monetaria.

Comparativo de curules asignadas realmente y curules asignadas hipotéticamente en los municipios del estado 1992-2004

En el cuadro 3 se muestra también la manera en que el fenómeno de la sub y la sobrerrepresentación se presenta en los cinco ayuntamientos de Baja California por lo que hace al número de distritos (escaños) asignados a cada uno de ellos.

Quisiera precisar que el concepto de curules asignados realmente proviene de lo que normativamente se determinó para cada municipio, mientras que la asignación hipotética es el cociente que resulta de dividir el número de electores habilitados (E) del municipio entre la razón estatal (cuota de electores estatal por curul).

\section{A) SOBRERREPRESENTACIÓN}

Las inferencias que podemos derivar es que durante todo el periodo analizado (1992-2004) estuvo siempre presente algún nivel de desaveniencia entre curules asignadas realmente y curules hipotéticas que debieron corresponderle a cada municipio. Como podemos ver, en los cinco procesos electorales siempre los municipios de Mexicali y Tecate registraron algún nivel de sobrerrepresentación, es decir, les fue asignada una cuota de representación que no les correspondía, mostrándose un nivel de ventaja en la representación con relación al resto de los municipios.

Este nivel de sobrerrepresentación de Mexicali resulta notoriamente progresivo sobre todo en los años 2001 y 2004, en los cuales el nivel de sobrerrepresentación alcanza la cantidad de un diputado excedente, pues mientras que la asignación real es de seis, en ambos años la asignación que debió corresponder de acuerdo a la razón estatal fue de 5.04 y de 4.94 diputados respectivamente.

La situación de sobrerrepresentación en el municipio de Tecate es también notoria pues desde 1992 a este municipio se le adjudica realmente un distrito y por lo tanto un diputado, sin embargo, si se anali- 


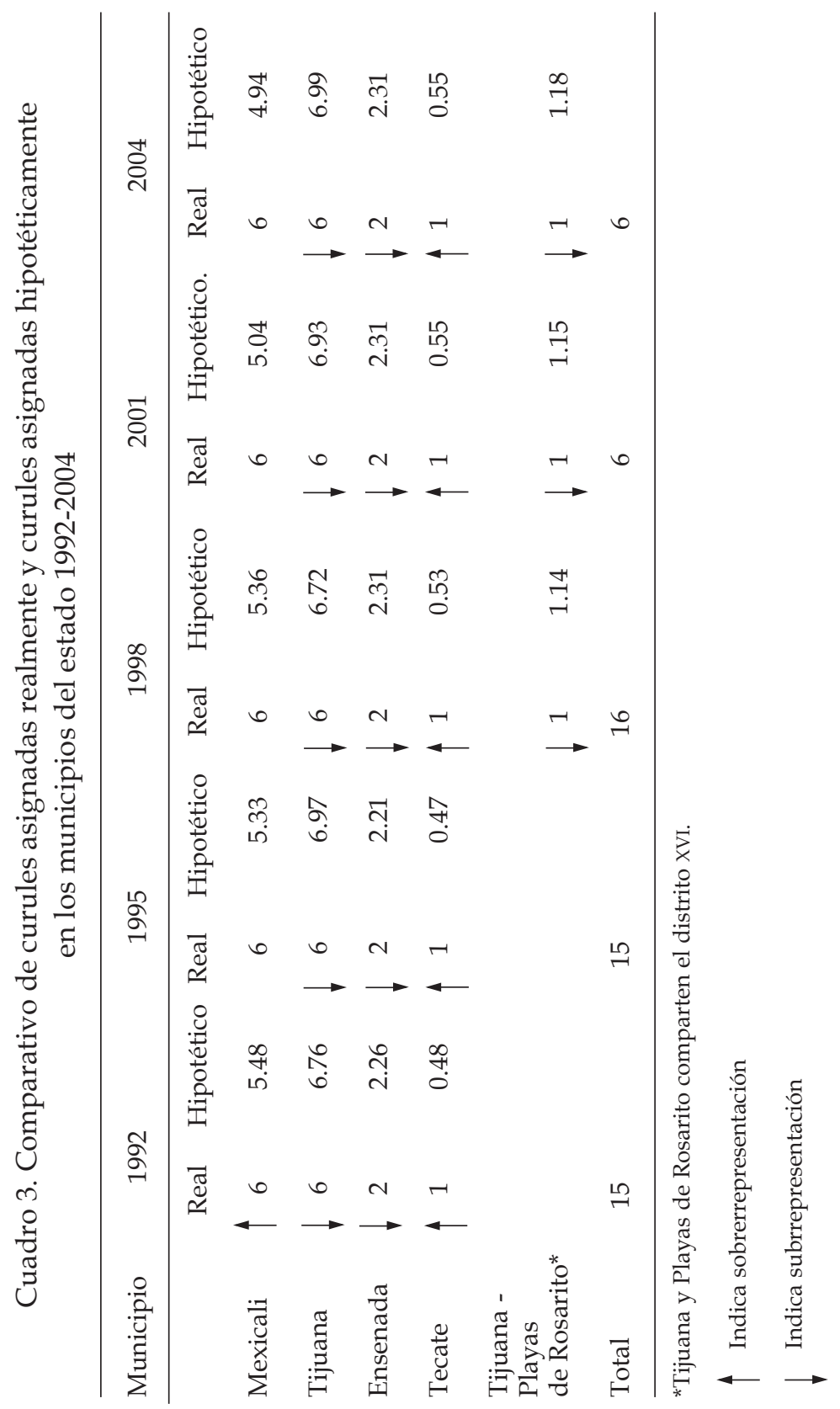


za su trayectoria durante el periodo de estudio se encontrará que nunca obtuvo la cantidad necesaria de electores habilitados para obtener legítimamente dicha representación. Éste es el caso más atípico pues parece muy evidente que el desfase que favorece a este municipio, dada su alta desavenencia con la asignación hipotética durante toda la trayectoria, puede explicarse por el uso de un criterio terraorientador que privilegió el principio de la representación de una población justificada sólo espacialmente; esto es posible a reserva de comprobar que hubiera algún otro motivo de tipo político en virtud de una historia de lealtades de la conducta electoral de dicho municipio.

\section{B) SUBRREPRESENTACIÓN}

Por su parte, los municipios restantes, es decir, Tijuana, Ensenada y la zona Tijuana-Playas de Rosarito han registrado durante el periodo de estudio datos que confirman un determinado grado de subrrepresentación, ya que, siguiendo los datos del cuadro anterior, este fenómeno es gradualmente creciente en todos ellos. Destaca sobre todo el caso de Tijuana, ya que dicho municipio poseyó siempre seis distritos electorales y por lo tanto seis diputados como producto de la asignación real, pero atendiendo a la razón estatal y de acuerdo a los electores potenciales, debiera tener adjudicado un distrito más. Si bien en los casos de Ensenada y Tijuana-Playas de Rosarito la subrepresentación es menor, lo de Ensenada podrá mutarse en una situación crítica si no se aplica alguna solución al respecto, dado que la diferencia entre los distritos asignados realmente y los hipotéticos, sobre todo en las últimas tres elecciones (1998, 2001 y 2004), registra un índice de superávit que representa una tercera parte de la unidad (escaño).

En suma, con respecto a este indicador podemos agregar varias cosas: una de ellas es que el caso de Baja California amerita un estudio profundo y un seguimiento muy cercano pues, como hemos visto, esta entidad registra un fenómeno de malaporcionamiento estable y gradualmente creciente, lo que puede tener dos explicaciones: 1. que exista una falta de destrezas técnicas y de conocimiento de los agentes públicos en quienes recae la atribución de diseñar y rediseñar las circunscripciones distritales, así 
como de valorar los efectos que produce en el campo del sesgo de representación; 2. que medie una decisión deliberada a efecto de agenciarle alguna utilidad electoral a alguna de las fuerzas políticas presentes en los diversos territorios de la entidad. Esta última opinión se lanza sólo como una hipótesis de trabajo y como aseveración empírica aún no sustentable.

Ahora bien, tomando a los municipios como unidades de representación poblacional, históricamente ha existido un índice de reducción de la representación por lo menos durante el periodo de estudio. Esto quiere decir que los ciudadanos de los municipios de Tijuana, Ensenada y Tijuana-Playas de Rosarito tienen permanentemente asignada una cuota de valor de decisión política menor que los ciudadanos de Mexicali y Tecate. También en este caso vale la pena esbozar algunas hipótesis para desentrañarse en otro momento, y una de ellas se relaciona con la posibilidad, como consecuencia del desbalance representativo municipal, de atraer algunos beneficios en la construcción y ejecución de la agenda legislativa y gubernamental en detrimento de los municipios subrrepresentados. Una segunda hipótesis sería que, considerando la rivalidad histórica entre el municipio de Mexicali y el de Tijuana, el grupo político dominante resuelva reducir la influencia representativa y política del municipio de Tijuana.

\section{Indicadores de malaporcionamiento}

en los municipios del estado 1992-2004

La magnitud de la sub y la sobrerrepresentación (malaporcionamiento) puede medirse a través del índice Difmap, el cual indica la magnitud de la desviación que se produce en la representación asignada de diputados por cada unidad subnacional de que se trate, ya sea un municipio o un distrito electoral uninominal, en relación directa a la cantidad de electores habilitados en términos porcentuales de cada municipio.

De darse puntualmente el principio de la igualdad del voto, el resultado hipotético de esta relación (\% M - \% E) debería ser igual a cero, dado que, a una determinada cantidad porcentual de ciudadanos en 


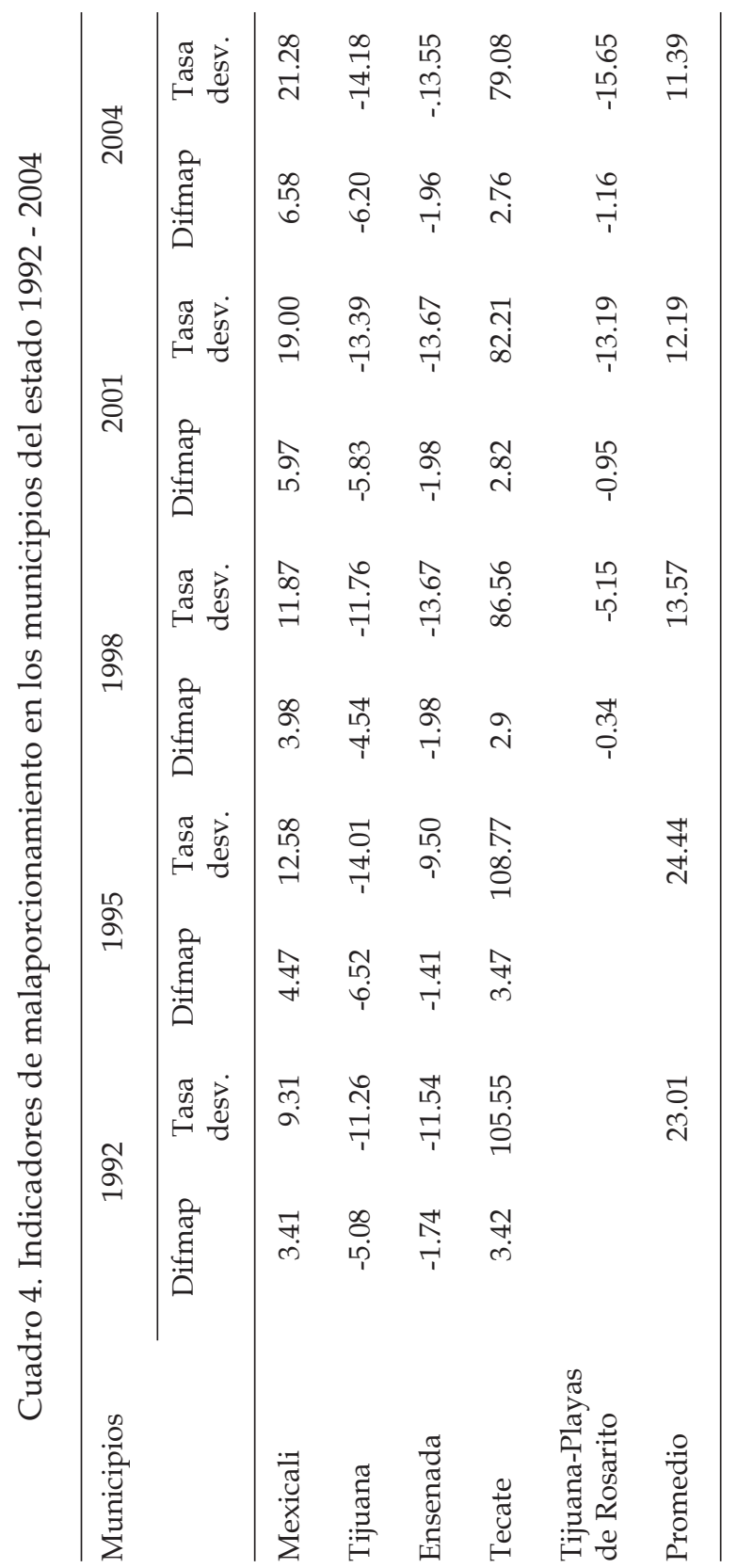


la unidad subnacional municipal debiera corresponder una cantidad porcentual similar de representantes.

Este indicador es el que refleja con mayor claridad la existencia de malaporcionamiento, ya que establece la compatibilidad entre las dos cifras que determinan la igualdad de los mandatos que se deben adjudicar a cada unidad subnacional respecto de los electores habilitados.

A diferencia del indicador anterior, éste refleja la relación directa entre lo que representan porcentualmente los distritos asignados al municipio respecto del total de la Cámara de Diputados (de mayoría relativa) y lo que representan porcentualmente los electores habilitados del municipio respecto del total de los electores habilitados de la entidad. Por este motivo, las magnitudes del sesgo parecen moderarse, ya que un desfase excesivo puede gestar un modelo distrital demasiado inicuo y con elementos notorios de ilegitimidad, efecto que el sistema electoral ha cuidado no provocar.

El indicador Difmap puede interpretarse no sólo como sobre y subrrepresentación, sino que también de alguna forma significa de manera comparativa el nivel de sustracción de una porción de la cuota de valor de decisión política asignada a cada ciudadano, ya que la coincidencia o la falta de ella entre los dos índices (diputados y electores habilitados) está asociada a la hipótesis de que el diseño se considera a nivel de un sistema distrital equitativo e inscrito en un plano de totalidad, por lo que cualquier práctica que genere sobrerrepresentación implicará en consecuencia una subvaloración de aquellos ciudadanos que se encuentren en una situación contraria, ya sea en la propia unidad subnacional o en otra correspondiente a la misma entidad.

\section{A) SOBRERREPRESENTACIÓN}

Por lo que se refiere al indicador Difmap, el cuadro 4 corrobora lo que hasta ahora se ha señalado en el sentido de que durante el periodo de estudio son los municipios de Mexicali y Tecate los que presentan indicadores de sobrerrepresentación, observándose sin embargo que en el caso de Mexicali éste registra una tendencia progresiva que se 
acentúa notoriamente e incluso llega casi a duplicar el nivel de sobrerrepresentación entre 1992-2004 respecto a 1992 y 1998.

Por su parte, por lo que toca al municipio de Tecate se observa que la tendencia es decreciente, pues partiendo de 3.42 Difmap en 1992 concluye con 2.76 en 2004.

Lo que esto quiere decir es que, en el caso de Mexicali, el grupo de electores habilitados ha crecido (E) a menor ritmo que el total de electores habilitados a nivel estatal, mientras que el número de diputados (M) o de distritos ha permanecido invariable, por lo tanto, el rubro de ciudadanos se aleja cada vez más del total estatal.

Por su lado, en el caso de Tecate se expresa un fenómeno en el cual el representante cameral es invariablemente uno, mientras que el ritmo de crecimiento de los electores habilitados y de su composición respecto del total estatal de electores habilitados cada vez fue mayor.

\section{B) SUBRREPRESENTACIÓN}

A este respecto, los tres municipios restantes (Tijuana, Ensenada y Tijuana-Playas de Rosarito) muestran una tendencia permanente de subrrepresentación, destacándose sobre todo Tijuana, municipio que registra un espectro visiblemente irregular. En este caso habría que rescatar que existen dos momentos (1995 y 2004) en los que los datos prácticamente coinciden con un alto indicador Difmap de -6.52 y -6.20 respectivamente, pero, como se observa, es este municipio junto con Tijuana-Playas de Rosarito el que termina el periodo con dos momentos (2001 y 2004) con los registros más altos correspondientes a este indicador. Esto significa que existe un alto ritmo de crecimiento de los electores habilitados en la unidad municipal con relación a los electores habilitados a nivel estatal, y dado que la cantidad de distritos es invariable, ello se refleja en la falta de compatibilidad entre ciudadanos y representación asignada.

Por lo que se refiere al indicador tasa de desviación, ésta nos indica el sesgo que existe en la unidad subnacional por lo que respecta a la hipotética correspondencia del porcentaje de distritos electorales (escaños) del municipio del total de distritos electorales del Estado, entre 
el porcentaje de electores habilitados que corresponde al municipio del total de electores del estado.

Es decir, la desviación está dada por una correspondencia hipotética exacta o no igual a uno, ya que en un sistema electoral cuyo principio es la igualdad del voto ello debe traducirse en una igualdad de la representación. De esta manera, cualquier alejamiento de dicha premisa produce variables no coincidentes.

En función de lo antes dicho, podemos afirmar que Baja California conforma un sistema de representación asimétrico en donde, atendiendo a la distribución de escaños por municipio, existe una desviación constante respecto a los electores habilitados durante la trayectoria del periodo 1992-2004.

Si bien observamos que el promedio de la tasa de desviación se ha reducido en forma gradual y sostenida (en 1992 significaba 28.78 puntos y en 2004 registra 11.39 puntos), lo interesante es observar el significado del índice de desviación de acuerdo a cada municipio.

\section{C) TASAS DE DESVIACIÓN POSITIVA}

En este caso se encuentran los municipios de Mexicali y Tecate durante todo el periodo. De esta trayectoria destaca el ritmo ascendente de Mexicali, el cual registra un desvío de 9.31 puntos en 1991 hasta 21.28 en 2004, esto significa un aumento más allá del 10.0\%, es decir, que la asimetría de la relación representación/electores lejos de corregirse se ha ido deteriorando. Por su lado, en el caso de Tecate la dinámica es contraria pues el desvío de 105.55 puntos de 1992 se reduce a 79.08 puntos, lo cual se explica por la dinámica de los electores habilitados a un ritmo creciente modificando con ello esta parte de la estructura estatal, sin embargo, es éste municipio el que registra la más alta tasa de desvío.

No deja de llamar la atención el caso de Mexicali, pues no obstante la estabilidad de la asignación de distritos, la tasa de desviación muestra índices ascendentes, lo cual se explica porque la dinámica de crecimiento de electores siempre ha sido menor que la estatal, así como con respecto a la de Tijuana y la zona de Tijuana-Playas de Rosarito. 
D) TASAS DE DESVÍO NEGATIVAS

En este caso se encuentran los municipios de Tijuana, Ensenada y Tijuana-Playas de Rosarito, los cuales registran durante todo el periodo tasas de desvío negativas. Destaca por su dinamismo la zona Tijuana-Playas de Rosarito, pues del dato registrado en 1998 que representa -5.15 puntos se desplaza hasta -15.65 puntos en el 2004, triplicando el indicador.

También observamos que el municipio de Ensenada registra una tendencia estable, sobre todo a partir del año de 1998, registrando hasta 2004 prácticamente la misma tasa de desvío.

Por su parte, Tijuana presenta la tendencia más inestable durante todo el periodo, aunque siempre con diferenciales mínimas entre una fecha y otra. Termina también con una alta tasa de desvío en 2004 con -14.18 .

De similar manera que el indicador anterior, éste registra no sólo el nivel del malaporcionamiento que corresponde a cada municipio del estado, sino también el grado de ponderación desigual del valor electoral de un grupo de ciudadanos en detrimento del valor de otros. Éste es el caso de aquellos municipios que registran una tasa de desviación positiva, ya que en éstos es mayor la representación asignada que la que les debería corresponder de acuerdo a la magnitud de los electores habilitados del municipio.

En esta circunstancia, el referente es que tanto la representación cameral como los electores municipales conforman un sistema estatal integrado tanto de representantes como de electores, por ello cualquier nivel de no correspondencia entre ambos indicadores (distritos electorales y electores habilitados) que se registre en cualquier municipio provocará una asimetría en los otros.

\section{Conclusiones}

Sin duda es éste un tema poco estudiado y, me atrevo a asegurarlo, de no ser por el trabajo politológico de Diego Reynoso pocos analistas interesados en los temas de sistemas electorales hubiéramos podido iniciarnos en él. 
Sin embargo, cuando desplazamos una mirada al paisaje nacional, sobre todo en los espacios estatales y municipales, encontramos para nuestra sorpresa que existe una cantidad importante de entidades en las cuales el fenómeno de la sub y la sobrerrepresentación se encuentran fuertemente arraigados, cosa que no sucede a nivel nacional, tal vez por la mayor atención puesta por los actores políticos a este tema.

El estudio de los sesgos en la representación de las entidades es un tema que debiera ser casi cotidiano, por ello la acometida al tema que hoy ofrecemos pretende iniciar el estudio sistemático de este fenómeno en nuestra entidad a efecto de gestar correcciones cuando el malaporcionamiento rebase los límites de la legitimidad.

A partir del estudio sobre este fenómeno en Baja California durante el periodo 1992-2004 se exponen los siguientes hallazgos:

1. Durante el periodo analizado, Baja California registra en los dos sentidos una magnitud del malaporcionamiento, es decir, que los municipios del estado muestran una tendencia permanente y constante de sobrerrepresentación y de subrrepresentación.

2. Existe una tendencia constante de sobrerrepresentación en los municipios de Mexicali y Tecate, este último con un altísimo registro de sobrerrepresentación con una tasa a la baja pero a un ritmo muy lento. En sentido inverso, el municipio de Mexicali revela una tendencia a la alta a un ritmo relativamente acelerado.

3. Hay una tendencia constante de subrrepresentación en los municipios de Tijuana, Ensenada y la zona Tijuana-Playas de Rosarito. Tijuana y Tijuana-Playas de Rosarito destacan por expresar los más altos índices de subrrepresentación, y en forma especial este último por un alto ritmo de crecimiento del indicador tasa de desvío.

4. Si bien todo parece indicar que para la elección estatal de 1998 la autoridad electoral efectuó algunos ajustes al diseño distrital, lo cierto es que los municipios y los distritos en ellos contenidos recuperan la dinamicidad de su trayectoria general. Esto nos habla de que en este nuevo diseño fueron tomados en cuenta, además del criterio demoorientador (poblacional), otros crite- 
rios de orden terraorientador: geográficos, demográficos, naturales y otros.

5. Por todo lo señalado, y de acuerdo con las inferencias derivadas del análisis de los diversos indicadores, resulta plausible actualizar la discusión de la tensión que provoca el concepto de igualdad del voto como premisa de modelo democrático, enfrentado a una desigualdad de la representación que los datos empíricos arrojan en el ámbito de las unidades subnacionales (municipios).

En efecto, con los datos aquí señalados se actualiza la discusión sobre los criterios que deben prevalecer en las entidades del país respecto a los diseños para determinar el sistema de distritos electorales, tomando en consideración el acatamiento irrestricto de la regla constitucional a fin de no generar controversias y la suspicacia de los actores políticos al constituir distritos electorales con sesgos evidentes que cristalizan en una práctica de sobre y subrrepresentación, lo cual, como ya se señaló, puede propiciar inconformidades y desavenencias de tal magnitud que pueden ser transferidas incluso para su resolución a los tribunales correspondientes. Insisto en que esta práctica pone en tensión el principio democrático de "igual cuota de valor de decisión a cada ciudadano", pues de acuerdo a varios de los índices (Difmap y tasa de desviación) aplicados en el presente estudio se pudo demostrar que durante la trayectoria analizada existe lo que podríamos llamar "una cuota de sustracción del valor de decisión" a un grupo de ciudadanos en beneficio de otros; tales son los casos de los ciudadanos de los municipios de Tijuana, Ensenada y Tijuana-Playas de Rosarito en beneficio de los de los municipios de Mexicali y Tecate.

Construir la simetría del sistema de representación de Baja California implica realizar un esfuerzo muy relevante a efecto de que los nuevos límites distritales permitan recuperar la normalidad, ya que de darse elecciones en las que el partido triunfador obtenga una reducida diferencia respecto del segundo lugar, seguramente el tema de los diseños distritales y la subvaloración electoral de un grupo de ciudadanos se volverá un tema de profunda controversia con una dinámica social y un resultado de gran incertidumbre. 


\section{Bibliografía}

Schedler, Andreas (2004), "La incertidumbre institucional y las fronteras borrosas de la transición y consolidación democráticas", Estudios Sociológicos, núm. 64, México, CIDE.

Cossio Díaz, José Ramón (2005), “Un ciudadano un voto”, Voz y Voto, núm. 154, México, Nuevo Horizonte.

Alcubilla, Arnaldo Enrique (1999), "Sufragio", Diccionario Electoral, Costa Rica, Capel.

Bovero, Michelangelo (2002), Una gramática de la democracia, Madrid, Trotta.

Nohlen, Dieter (1994), Sistemas electorales y partidos políticos, México, FCE.

Pitkin, Hanna Feniche (1985), El concepto de representación, Madrid, Centro de Estudios Constitucionales.

Reynoso, Diego (2004), Votos Ponderados, México, Porrúa. (2001), “Distritos y Escaños en Brasil: antecedentes, diagnóstico y consecuencias partidarias del malaporcionamiento", Política y Gobierno, núm. 1, primer semestre de 2001, México, CIDE. (2002), "Las consecuencias políticas de la sobrerrepresentación distrital", Política y Gobierno, núm. 2, segundo semestre, México CIDE.

(1999), "La desigualdad del voto en Argentina", Perfil Latinoamericano, núm. 15, diciembre, México, FLACSO.

(2005), "Sobrerrepresentación distrital y sesgos partidarios. El caso de Nuevo León", Estudios Políticos, núm. 4, México, UNAM. (2004), "La sobrerrepresentación distrital electoral en Sonora y Sinaloa, 1994-2004: sus efectos en perspectiva comparada", Región y Sociedades, núm. 29, México, El Colegio de Sonora.

Vallés, Joseph (1997), Sistemas electorales y gobierno representativo, Madrid, Ariel.

Sánchez Navarro, Ángel (1998), Constitución, igualdad y proporcionalidad electoral, Madrid, Centro de Estudios Políticos y Constitucionales.

Varela, Elena (2005), "Penélope y la democracia mexicana", Este País, núm. 177, diciembre México, Dopsa. 